\title{
A educação contemporânea, o combate à pobreza e as demandas para o trabalho do assistente social: contribuições para este debate
}

\section{Contemporary education, the fight against poverty and the demands for the social worker's work: contributions to this debate}

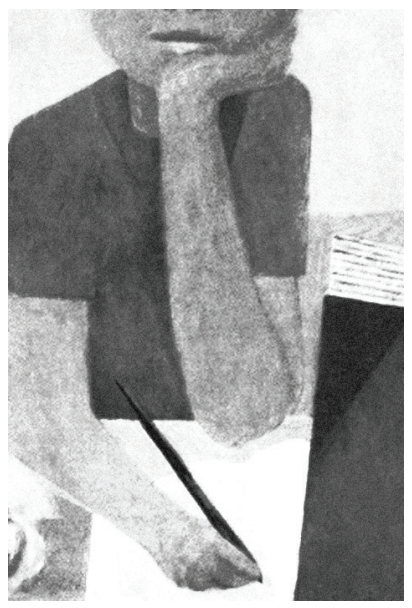

Feliz daquele que transfere o que sabe e aprende o que ensina.

Cora Coralina

\section{Simone Eliza do Carmo Lessa*}

Resumo: Apresentamos discussão sobre a complexa relação entre a educação como política pública e a vinculação do Serviço Social a ela, em especial, sua integração à escola pública, neste momento de crise do capital. Trata-se de um debate relevante e crescente que atrai muita atenção por seu aprofundamento recente e pela ampliação de vagas na área.

Palavras-chave: Educação. Crise capitalista. Escola pública. Serviço Social.

\begin{abstract}
We introduce the debate on the complex relationship between education as a public policy and the Social Service link to it, in particular, its integration into the public school at the current moment of crisis of the capital. It is an important and growing debate which attracts a lot of attention for its recent deepening and expansion of jobs in the area.
\end{abstract}

Keywords: Education. Capitalist crisis. Public school. Social work.

* Assistente social do Instituto de Aplicação Fernando Rodrigues da Silveira (UERJ) e doutora em Serviço Social pela Universidade Federal do Rio de Janeiro (UFRJ), Brasil.E-mail: elizasimone@gmail.com. 


\section{Introdução}

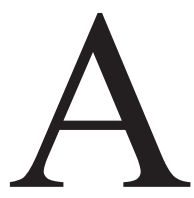

significativa presença de assistentes sociais e estudantes de Serviço Social no recente Encontro Nacional Serviço Social na Educação realizado pelo conjunto CFESS/Cress em Alagoas ${ }^{1}$ — com audiência em torno de mil presentes ${ }^{2}$ - demonstra o crescente interesse da profissão em torno deste tema e área de trabalho. Concursos recentes para assistentes sociais nos Ifets (Institutos Federais de Educação, Ciência e Tecnologia) e universidades públicas - para atuação, especialmente, na assistência estudantil — e prefeituras - para ações de acompanhamento das expressões da questão social nas escolas - também revelam a ampliação de vagas no campo educacional.

Nesta mesma linha de raciocínio, destacamos a existência de projetos de lei que recomendam a presença de assistentes sociais e psicólogos no ensino básico, tal como o Projeto de Lei n. 60/2007, em tramitação na Câmara Federal. Ainda no âmbito legal, a Lei n. 12.101/2009 (Brasil, 2009) trata da obrigatoriedade das chamadas instituições educacionais filantrópicas de disponibilizarem bolsas de estudos aos estudantes que se encontrarem em fragilidade socioeconômica (tornando, estes espaços, importantes empregadores de assistentes sociais), além da recentíssima Lei n. 12.677/2012 (Brasil, 2012), que dispõe sobre a criação de cargos efetivos para profissionais da educação junto ao MEC, dos quais 589 são para assistentes sociais. Partindo destes elementos, entendemos a necessidade de ampliarmos o debate sobre o trabalho de assistentes sociais no campo da educação, e é isso que nos propomos na presente reflexão. Para tanto, partiremos dos elementos da totalidade em que a educação contemporânea se inscreve, buscando atentamente suas particularidades. Neste percurso, discutiremos a educação como política pública na sociedade atual, a ampliação do acesso a ela, a fragilização de sua qualidade, suas interfaces com outras políticas públicas, seus dilemas e suas potencialidades.

Não resta dúvida de que a educação é um assunto que desperta grandes e contraditórios interesses por parte do capital e dos trabalhadores. A recente mobilização de setores progressistas da sociedade brasileira ${ }^{3}$ em prol da garantia da

1. Em junho de 2012.

2. O evento também esteve disponível para acesso na internet, em tempo real, o que ampliou a audiência.

3. Estavam mobilizados em torno desta mobilização em prol da garantia dos $10 \%$ do PIB entidades como o CFESS, ABEPSS, Andes, Anel, Conlutas, Sepe. 
aplicação dos $10 \%$ do PIB na educação e, sob um outro prisma, o fato de que o Plano Nacional de Educação, em debate no Congresso Nacional, propor a aplicação de somente $7 \%$ do PIB e a longo prazo (somente em 2020!) são expressões deste processo de interesses diversos. ${ }^{4}$

Na compreensão de tais tensões em torno de projetos educacionais distintos, precisamos apreender os movimentos contraditórios em que a educação se insere. Neste sentido, lembramos que o capital, em especial na contemporaneidade, não pode prescindir da educação por diversos fatores, dentre os quais destacamos: seu imenso potencial de otimização da produtividade e do lucro, sua capacidade de potencializar avanços tecnológicos, bem como suas possibilidades de formar nichos produtivos importantes para o capital e para a ordem vigente. Além disso, precisamos pensar a educação frente à mundialização da pobreza (Chesnais, 1996) por sua capacidade de preparar os mais pobres para uma vida produtiva subordinada e desprotegida, mas denominada ideologicamente empreendedora. Somado a este quadro, frente à crise atual do capitalismo — relacionada à superprodução, à queda dos padrões de consumo, à crescente desproteção social, ao endividamento de indivíduos, empresas e Estados e à financeirização da economia (Gonçalves, 2008) - a educação recebe enfoque especial pelas potencialidades aqui já elencadas.

O capital, diante da referida crise, lança expectativas de novo tipo à produção e à circulação de conhecimento - agora convertido em mercadoria vendável - e para as políticas educacionais. Tais políticas têm sido maximizadas em suas potencialidades, por parecerem conter respostas para este momento em que os horizontes da proteção social se estreitam, o desemprego cresce, o subemprego idem. Neste sentido, enquanto a previdência, a assistência social e a geração de postos de trabalho protegidos, por exemplo, recebem duras críticas (a primeira é vista como deficitária, a segunda como favorecedora de uma postura de resistência ao trabalho e a terceira como cara e sobretaxada), a educação parece dotada somente de qualidades, em especial no que tange à qualificação permanente de mão de obra para acesso ao emprego. Educar, portanto, parece ser um negócio lucrativo ${ }^{5}$ em vários sentidos.

4. Lembremos que hoje, cerca de 5\% do PIB são aplicados na educação.

5. Não por acaso, o segmento educacional privado tem crescido significativamente. Como afirmam empresários do setor, em recente entrevista, a área de educação privada experimenta grande competitividade entre as empresas (D’Elboux, 2012). 
Na sociedade contemporânea, a tecnologia tem assumido lugar de grande destaque, mesmo nos países periféricos, nos quais sua presença ainda é frágil. Este quadro não é uma novidade, visto que ao longo do século XX bens produzidos pela ciência e pela tecnologia se aproximaram do cotidiano, através do consumo (Hobsbawm, 1995). O que vemos como um elemento novo é o fato de que os avanços tecnológicos foram apropriados pelo capital de maneira a criar a falsa imagem de que estamos em uma sociedade futurista, de aparência imaterial, estruturada sobre o conhecimento ${ }^{6} \mathrm{e}$ não mais sobre o trabalho humano. Tal situação se materializa na maximização do valor dos processos educativos e da aprendizagem permanente.

Segundo esta concepção — não coincidentemente reforçada por organismos de financiamento internacional, como o Banco Mundial — o conhecimento é um bem que está disponível a todos, a despeito da condição de classe. Este novo bem econômico seria o principal recurso da economia globalizada, ou seja, seria um "novo capital", passível de ser conquistado por empenho de ordem individual.

Esta é, no entanto, uma interpretação falaciosa da realidade, que revela a aparência de um fenômeno e não o fenômeno em si (Kosik, 1995), visto que não estamos diante de uma efetiva valorização do conhecimento em sentido amplo e da educação em particular. Lembremos de Harvey (2003), que nos fala da sociedade pós-moderna que valoriza o efêmero, o imediato, o fugaz, o que certamente está em oposição à ideia do conhecimento aprofundado, que exige tempo e dedicação para ser alcançado. A educação e o conhecimento como bens, portanto, são falaciosos e não estão acessíveis a todos. Muito ao contrário disso. O acesso e a qualidade da educação permanecem atravessados pela condição de classe do educando: quanto mais precárias suas condições de vida e trabalho, mais fragilizadas suas possibilidades de aprendizagem.

Desta forma, a ideia da centralidade do conhecimento, afinada que está com o ideário pós-moderno (Harvey, 2003), não se materializa no sentido da valorização do homem e da mulher em suas potencialidades e possibilidades de aprendizagem, concretizando-se, de fato, na sua utilização como instrumento de agregação de valor ao capital e de atendimento às demandas do mercado. Frigotto (1995, p. 56) critica esta perspectiva, classificando-a como um "rejuvenescimento da teoria do

6. Frigotto (1996, p. 35) analisa e critica o pensamento de Toffler que nos apresenta a tese de que o proletariado seria substituído pelo cognatariado, os homens do conhecimento, num mundo em que o trabalho, como categoria ontológica, supostamente, teria sido substituído por outras mais centrais, como a cultura, o pensamento religioso, o lazer. 
capital humano". ${ }^{7}$ Este tipo de concepção, além de rejuvenescer a Teoria do Capital Humano, desqualifica debates realizados desde os anos de 1960 (inicialmente por Bourdieu), ${ }^{8}$ que refletem sobre a intensa influência da origem sociocultural (e, acrescentamos, de classe), na escola. $\mathrm{O}$ debate em torno do conhecimento como um bem econômico, portanto, retrocede em termos de pensamento educacional.

Em tempos de aparente centralidade do tema educação e de ampliação do acesso à escolarização ${ }^{9}$ é importante que possamos problematizar tais ideias, bem como o quadro em que está sendo desenhada a Educação brasileira hoje. É isso que pretendemos no próximo item.

\section{Desenvolvimento: mais vagas e mais permanência frente à fragilização da escola pública}

Partimos do princípio de que a educação é uma relação social e, como tal, em uma sociedade capitalista, precisa ser entendida como resultado de tensões de classe e dos elementos que lhes são decorrentes. Portanto, precisa ser compreendida como processo influenciado intensamente pela organização da base produtiva, pelas formas de gestão da mão de obra, pela organização dos trabalhadores e do capital, tendo o Estado como mediador de tais relações e executor de políticas sociais. A educação, portanto, influencia e é influenciada pela produção e reprodução das relações sociais, sendo objetivada nas vidas humanas. Assim, educar supõe o desenvolvimento do indivíduo como subjetividade e como ser coletivo. Educar é, ainda, um ato político, materializado em uma política pública.

Observemos um dado recente desta política para, a seguir, nos reportarmos, brevemente, a alguns elementos de sua história. A ampliação do acesso às vagas no

7. Segundo Frigotto (1993, p. 38), a chamada Teoria do Capital Humano teve sua formulação sistemática no final da década de 1950, momento em que "as relações intercapitalistas demandavam e produziam este tipo de formulação". Esta compreensão da realidade postulava o acesso à educação como instrumento de equalização social. Neste sentido, o crescimento do processo de escolarização conduziria à mobilidade social.

8. Ver em Bourdieu (1992).

9. O Ministério da Educação e Ciência (MEC), através do Censo Escolar/2010, registra 51,5 milhões de estudantes matriculados no ensino básico, nas redes pública e privada do Brasil (Brasil, 2010). Esta mesma fonte revela que temos $97 \%$ das crianças matriculadas no ensino fundamental. 
ensino fundamental (em especial público) deve ser entendida em sua complexidade frente a uma sociedade industrializada, na qual o acesso ao conhecimento letrado se populariza e onde o mundo do trabalho solicita cada vez mais uma mão de obra detentora de conhecimentos - simples, para a grande maioria (Kuenzer, 2001) - focados na produção, que precisam ser requalificados permanentemente (Antunes, 1999).

A referida ampliação do acesso à escola — divorciada que está da qualidade do ensino - não tem sido acompanhada da infraestrutura necessária para a organização de uma educação nacional de qualidade. Neste sentido, somada à tal ampliação, destacamos como fenômeno contemporâneo da educação no Brasil a valorização de ações de voluntariado, ${ }^{10}$ com a consequente desprofissionalização dos educadores. Destacamos, ainda, as aprendizagens profissionais dissociadas de fundamentação científica, realizadas fora dos ambientes formais, com vista ao ingresso e reingresso no mundo do trabalho (ainda que não necessariamente, o formal), bem como aquelas de qualidade fragilíssima como o chamado "ensino a distância". Também são expressões deste quadro programas como o Prouni, ${ }^{11}$ que isentam instituições de ensino superior de impostos e podem transferir recursos públicos para iniciativa privada, bem como a compra de serviços educacionais públicos, que poderiam ser obtidos através de instituições públicas, mas que são adquiridos através de ONGs e Oscips (Organizações da Sociedade Civil de Interesse Público).

A expansão deste quadro gera um modelo de formação precarizada, simplificada, produtivista, que desqualifica o público e valoriza o capital privado, trazendo para a instituição escolar novos desafios, ${ }^{12}$ especialmente no ensino fundamental

10. O Programa Amigos da Escola, da Fundação Roberto Marinho, é um exemplo emblemático deste processo.

11. O programa Universidade para Todos está em vigência desde 2004 e oferece bolsas de estudo parciais ou integrais em instituições privadas de ensino superior, para estudantes que comprovem renda familiar per capita entre um salário mínimo e meio a três salários mínimos. Vale ressaltar que compreendemos que estudantes fragilizados economicamente, para os quais o acesso à universidade pública parece impossível, desejem viabilizar esta expectativa através do Prouni. O que questionamos é o elitismo do acesso ao ensino superior público. Por que não democratizar o acesso a ele? Ao que tudo indica, parece estar sendo mais rentável para o governo federal e sua base de sustentação a manutenção do Prouni.

12. Manacorda (2000) reconstrói a história da escola moderna, relacionado-a à Revolução Industrial. Ele lembra que no seu interior a questão social sempre esteve presente e que, em alguns momentos,a instituição assumiu uma face assistencial. Este quadro, portanto, não é novo. Manacorda (2000) afirma que a escola passa, lentamente, com a solidificação da fábrica e da vida urbana, a assumir outros papéis, além da divulgação e troca de conhecimento: ela passa a se desenvolver no sentido da complementaridade da vida domés- 
— nosso foco de análise. Falamos da absorção e permanência precarizada de uma população extremamente pauperizada, privada de bens e de acesso a serviços públicos de qualidade, que reside, trabalha, se alimenta, tem acesso à cultura e ao lazer de forma precária, que passa a experimentar o espaço escolar mais cotidianamente. Em outras palavras, estamos diante de uma expansão do acesso e permanência na escola, sem que esta instituição tenha sido avivada no sentido do financiamento para se mostrar interessante, acolhedora, bela, capaz de dialogar com a cultura desta população ingressante, dotada de infraestrutura material e humana para o seu fazer diário. Falamos, portanto, que a expansão das vagas e a ampliação da permanência acontecem em um momento de intensa desqualificação social e política da escola pública, bem como diante da fragilidade dos recursos que a sustentam. ${ }^{13}$

Rememorando nossa história recente, lembramos que o direito à educação aparece na legislação educacional somente na Constituição de 1946, ainda assim condicionado à oferta de vagas existentes (Saviani, 2000). Portanto, o acesso à escola e o crescimento de sua visibilidade social é um fenômeno novo em nosso país. Neste sentido, lembramos de Cunha (1995), que afirma que a industrialização brasileira acontece independentemente da escolarização, ou seja, sem que a massa trabalhadora precisasse de uma formação específica para ser incluída no mundo fabril, aprendendo seus ofícios nos espaços de trabalho. Ressaltamos, ainda, que apesar de avanços no campo dos direitos sociais após a década de 1930, nossa primeira Lei de Diretrizes e Bases da Educação data somente de 1961 e a seguinte e atual, de 1996. Da mesma forma, nosso Plano Nacional de Educação foi enviado ao Congresso em 2010 e é ainda objeto de questionamentos por parte da sociedade civil mobilizada em torno do direito à educação pública, visto que apresenta proposta de educação aquém das necessidades do nosso povo e divergente do perfil de um país que alcançou o status de sexta economia do mundo.

Também lembramos que a expansão da escolarização de longas faixas populacionais, especialmente os mais pobres, é um fenômeno novo ${ }^{14}$ na experiência

tica, realizando atividades até mesmo de assistência. Quando isso começa a ocorrer, na segunda metade do século XVIII, já é possível perceber que a instrução das massas estava colocada como problema a ser enfrentando, em especial, pelo Estado Moderno.

13. Ver o debate em torno da destinação dos $10 \%$ do PIB aqui já realizado.

14. Cunha (1995) destaca que a economia brasileira tem prescindido, historicamente, da ampliação da educação da força de trabalho. Para esse autor, a industrialização e (incluímos) o contato com as novas tecnologias têm sido feito fora da escola e sem a melhoria da qualidade educacional. 
brasileira. Sobre o tema, acrescentamos que a recente permanência dos mais frágeis economicamente nas instituições educacionais é resultado da associação dos processos de ampliação da ação do Estado na proposição de políticas sociais, do aprofundamento da industrialização, urbanização e da contratualização no Brasil, bem como de programas sociais ${ }^{15}$ — os primeiros datados da década de 1990 — que condicionam escolarização e assistência social. Portanto, trata-se de fenômeno novíssimo e em construção que precisa ser acompanhado e problematizado, a partir do pressuposto de que a ampliação do acesso não é garantia de formação de qualidade.

Fundamentados em Savianni (2000) afirmamos que a educação e a escola pública brasileira do início do século XXI estão diante de uma base legal recém-construída e tímida — nossa atual LDB datada de 1996 - , minimalista e subfinanciada, de uma rede pública, em sua maioria sucateada, de profissionais da educação mal remunerados e que ampliam suas rendas através de múltiplos empregos (e suas consequências), frente a uma realidade complexa, portadora de novas demandas para este campo: lidar com as consequências do aprofundamento da questão social em suas diversas expressões, refletidas no espaço educativo, incorporar "novos profissionais" em seu cotidiano - inclusive assistentes sociais — sem perder de vista sua função precípua: a formação humana. Assim, frente a uma significativa ampliação do acesso e permanência no ensino fundamental, notadamente o público, e do campo de trabalho do assistente social na educação, destacamos a necessidade de a categoria aprofundar conhecimentos a respeito das questões que recortam esta política como um todo e a instituição escolar, em particular.

\subsection{O Serviço Social, a escola e a promessa do combate à pobreza}

O Serviço Social é uma profissão requisitada socialmente a partir do desenvolvimento da divisão social e técnica do trabalho, no capitalismo em sua fase monopolista (Netto, 2001). Somos alguns dos trabalhadores chamados a atuar sobre as sequelas criadas pela apropriação desigual dos bens gerados pela humanidade e

15. Macedo e Brito (2004) fazem a análise crítica dos programas sociais que aliam auxílio financeiro e permanência na escola, por sua ação focalizada, pelas dificuldades de efetivo acompanhamento e pela tímida transferência de renda. 
sobre as consequências da exploração da força de trabalho, fatos que permitem que grandes faixas populacionais fiquem à margem dos processos civilizatórios (Mészaros apud Frigotto, 1995). As políticas públicas são nosso campo principal de intervenção profissional: "O assistente social é o agente de implementação da política pública", [...] "nossa base de sustentação funcional ocupacional” (Montaño, 2003, p. 244). Nosso fazer profissional se faz, portanto, sobre as consequências de um modelo de acumulação explorador e degradante das relações sociais, da força de trabalho e da natureza, que se concretiza na desigualdade em suas diferentes faces: pobreza, adoecimento, violência, abandono, desinformação, alienação, sofrimento mental, entre tantas outras. ${ }^{16}$

$\mathrm{Na}$ contemporaneidade, inúmeros têm sido os desafios do nosso cotidiano profissional: atuar em políticas públicas precarizadas e subfinanciadas, muitas vezes com vínculos de trabalho precários e com baixa remuneração, atendendo a usuários que experimentam em seu cotidiano as consequências dramáticas das desigualdades sociais que marcam nosso país e que possuem impactos objetivos e subjetivos intensos em suas vidas.

No reconhecimento deste quadro, porém, não cabe o fatalismo. Cientes de nossa relativa autonomia, tal como os demais trabalhadores que buscam "remar contra a maré" da ordem social perversa e desigual estabelecida, apoiados em nossa competência teórica, técnica, ética e política, caminhamos em busca de resistência, da defesa aos direitos humanos e da valorização de uma cultura apoiada na cidadania (Yazbek, 2009). Para tanto, estamos fundamentados em uma formação que dialoga fortemente com o marxismo em sua crítica à sociedade capitalista, em nosso Projeto Ético-Político, no Código de Ética e na Lei de Regulamentação da Profissão.

A dimensão educativa de nossa prática nos espaços onde atuamos é visível e fundamental, visto que nossa ação vem sempre acompanhada da palavra, da informação, da troca, da escuta apurada (que deve ser crítica e solidária), do debate, situações em que percepções de mundo são difundidas, analisadas, questionadas. Esta importante característica política e educativa de nossa intervenção profissional se faz presente, como não poderia deixar de ser, também no campo da educação.

16. É bom frisar, porém, que tais condições de trabalho não são específicas do Serviço Social, mas de todos aqueles profissionais que atuam nas ações que configuram a chamada proteção social, em seu amplo escopo. 
Nesta área, ${ }^{17} \mathrm{o}$ assistente social tem estado mais recentemente atuando no âmbito da garantia do acesso, da permanência e da valorização da gestão democrática (Almeida, 2003), bem como na execução de programas sociais incorporados ou associados às instituições educacionais (como o Programa Bolsa Família, ${ }^{18}$ as cotas nas universidades, a assistência estudantil voltada para diversos segmentos de alunos, as ações formativas no contraturno escolar, a dinamização dos debates sobre temas transversais trabalhados na escola, por exemplo). Com base em nossa experiência profissional acrescentamos que temos também importante papel na construção de análises mais totalizantes em torno das expressões da questão social nos espaços educacionais, de modo a problematizar a percepção dos atores que ali atuam e formam sobre a família contemporânea, sobre as condições de aprendizado dos estudantes, suas condições de vida e trabalho, sua percepção sobre a escola e suas condições de permanência (e identificação) neste ambiente.

A ampliação deste espaço de trabalho é nova, mas não a inserção da profissão no campo da educação. Já na década de 1950, com o crescimento da intervenção estatal sobre a questão social e do aparato público brasileiro, o espaço educacional ganhava destaque no cotidiano de ação do assistente social, em especial no Sistema "S" e nas creches, denominadas "parques infantis" (então vinculadas à LBA), assim como em Centros de Educação Popular. Nas décadas de 1980 e 1990, a atuação de profissionais de Serviço Social no campo educacional vai se tornando mais expressiva (Almeida, 2003), em especial em ações no contraturno escolar, nos Centros

17. Os Encontros Estaduais Serviço Social e Educação promovidos pelo Cress/RJ, através de sua Comissão de Educação e pela FSS/PEPSS/UERJ, com o apoio do Prof. Dr. Ney Luiz Teixeira de Almeida, têm recebido cada vez mais profissionais interessados em debater o tema. Da mesma forma, o Cress/RJ tem organizado, anualmente, curso que debate a profissão no âmbito educacional, com uma média de 50 alunos/ ano, entre estudantes e profissionais. Também tem crescido o quantitativo de TCCs, dissertações e teses sobre o tema. Lembramos, ainda, que o CFESS, a partir de pesquisa junto aos assistentes sociais atuantes na área em 2011, produziu um documento denominado "Subsídios para o debate sobre o Serviço Social na Educação". Disponível: <www.cfess.org.br>.

18. O PBF atende a 13 milhões de famílias (MDS, 2012). O valor médio pago mensalmente pelo Programa está na faixa de noventa e seis reais mensais, segundo o Ministério do Desenvolvimento Social (MDS) e os valores transferidos variam de $\mathrm{R} \$ 32,00$ a $\mathrm{R} \$ 306,00$. Tal programa tem permitido a permanência de um número significativo de crianças e adolescentes que antes oscilavam entre a matrícula e o abandono escolar, ao longo do ano letivo, segundo pudemos verificar em nossa experiência profissional. Esta permanência tem evidenciado no cotidiano da escola expressões da "questão social" que anteriormente eram menos visíveis, o que é um aspecto positivo, mas precisamos sair da verificação e passar à ação. 
Integrados de Educação Pública, os CIEPs ${ }^{19}$ do Rio de Janeiro, bem como em iniciativas como as do então Bolsa Escola - programa de transferência de renda que antecedeu ao Bolsa Família.

O que vemos como novidade, na atual conjuntura, é a intensificação da presença da profissão no interior da escola, aliada à multiplicidade de expressões da questão social neste ambiente. A esta reflexão acrescentamos que as mudanças no perfil da família contemporânea e a complexificação das demandas para os processos formativos, hoje, são desafios novos neste campo. No primeiro aspecto, destacamos que as famílias brasileiras têm se transformado - menor fecundidade, maiores jornadas de trabalho implicando a necessidade de diversificação da rede de cuidados com os filhos (o que coloca para escolas e creches mais desafios), novos arranjos familiares (Nascimento, 2006), o que traz para o interior dos espaços educativos temas antes tratados privadamente (separações, adoecimentos, violência doméstica, relação entre pais e filhos, debates sobre gênero, problemas financeiros, por exemplo). Quanto à complexificação dos processos educativos, entendemos que uma sociedade urbana, industrializada, marcada pela tecnologia e por instrumentos de comunicação sofisticados, desigual e diversa, solicita às instituições formadoras tarefas de novo tipo. Portanto, novas práticas pedagógicas e atores formadores são incorporados a este processo.

Este quadro se inscreve em uma totalidade maior, contraditória, mutável, histórica, tensionada, que tem se expressado em um projeto de educação simplificado e aligeirado para os trabalhadores, marcado pela dualidade estrutural (Frigotto, 1993), que deve ser compreendido a partir da condição que ocupamos - como país - na divisão internacional do trabalho, visto que esta só nos solicita uma apropriação periférica do conhecimento (Bianchetti, 2001). Em outras palavras, o espaço ocupado pelo país na dinâmica internacional não demanda um projeto educacional que priorize a formação de cientistas, analistas e pensadores críticos, bastando que formemos majoritariamente (ainda que não exclusivamente) uma massa de executores de atividades produtivas simples.

Nesta mesma totalidade observamos, ainda, a elaboração de uma LDB que Savianni (2000) identificou como "minimalista", articulada a um modelo de Esta-

19. Os CIEPs (Centos Integrados de Educação Pública) foram os carros-chefes do governo de Leonel Brizola no estado do Rio de Janeiro. Trata-se de experiência de escola integral, elogiada pela infraestrutura material e criticada por não chegar às crianças que viviam em situações econômicas complexas que lhes impediam a frequência à escola, em especial as trabalhadoras. 
do frágil na execução e financiamento das políticas educacionais, ${ }^{20}$ que organiza uma formação empobrecida para os trabalhadores, determinada pelas necessidades do mercado e cimentada sobre a ideia das competências. ${ }^{21}$ A política educacional hoje, como afirmamos anteriormente, tem voltadas para si muitos holofotes. A esta é conferido um papel salvacionista, de destaque nos palanques dos políticos, como se todas as respostas aos problemas nacionais fossem decorrentes da ampliação do acesso à escola. Neste sentido, a ideia de que a simples elevação dos patamares educacionais - independentemente da infraestrutura para tanto e das condições de vida da população - será responsável por uma revolução em todos os campos tem grande apelo e visibilidade. Este tipo de discurso simplifica uma realidade que não pode ser compreendida nem transformada, exclusivamente, a partir do acesso à escola. Portanto, não basta a associação linear e simplista entre "escolarização-qualificação-emprego-superação da pobreza", uma vez que sabemos que ações focalizadas, emergenciais, descontinuadas, não redistributivas, ou seja, políticas sociais fragilíssimas e desarticuladas das econômicas, têm papel de marketing social (Campos, 2003), mas pouca ou nenhuma efetividade. A promessa integradora deste tipo de proposta de formação (Gentili, 2001), portanto, não se mantém de pé diante de um olhar mais atento.

Nesta mesma linha de raciocínio, apesar da pouca efetividade deste projeto no sentido de melhoria da educação, esta política tem sido chamada para responder a uma "velha-nova" tarefa: o combate à pobreza. ${ }^{22}$ Este convite, porém, não é novidade. A associação entre as ações da atenção à pobreza, com outras do campo educacional/formativo, estão presentes a partir da Modernidade, conforme salienta Manacorda (2000), ou seja, a associação entre a educação, a pobreza e a formação

20. Um exemplo concreto deste fato nos chama a atenção. O Brasil ficou em $53^{\circ}$ lugar em avaliação internacional de alunos, em um total de 65 países analisados. Neste estudo foram verificados avanços relativos à matrícula escolar, mas esta ampliação do acesso não foi acompanhada da qualidade do serviço prestado. Este estudo revelou, ainda, que as escolas públicas estaduais, inclusive as do Rio de Janeiro, um dos mais ricos estados da União, figuram entre as piores em termos qualitativos ( $O$ Globo, 7 dez. 2010).

21. Atributo cognitivo e atitudinal, solicitado ao trabalhador. Ser competente significa estar identificado e sentir parte da empresa e de sua filosofia, o que inclui formação geral, capacidade para gerenciar a si mesmo e ao outro, capacidade para o trabalho em grupo, produtividade (Frigotto, 1996). Bianchetti (2001, p. 20), por sua vez, ressalta que a noção de competência, cuja fonte é o discurso do capital, é dotada de extrema "plasticidade", exigindo que o trabalhador seja moldado segundo as necessidades da estrutura produtiva e da organização das empresas.

22. Aqui entendida como uma das manifestações da questão social e como fenômeno multidimensional (Silva, 2010), traduzido nas condições objetivas e subjetivas da vida. 
para o trabalho marca o capitalismo desde sua origem. Diferentes análises, dentre as quais destacamos as de Manfredi (2003), Cunha (1995) e Arantes e Faleiros (1995), demonstram que o Brasil, desde os tempos da Colônia, tem utilizado o aprendizado (em especial aquele destinado a formar trabalhadores) como estratégia de controle social das populações pobres.

Campos (2003), por sua vez, destaca que os temas relativos à pobreza assumem visibilidade na sociedade brasileira ao longo do século XX. Neste sentido, lembramos Vargas, também denominado de "Pai dos Pobres", bem como lembramos do debate sobre as Reformas de Base do governo Jango, da crítica à ditadura militar em seu aprofundamento das desigualdades, da retomada da democracia e da busca por direitos nos anos de 1980. Mais recentemente, lembramos o governo Lula da Silva e suas promessas quanto à reforma agrária e à melhoria das políticas de saúde e educação - que, se concretizadas, teriam grande impacto sobre a pobreza — falácias que, efetivamente, não se cumpriram.

Entendemos que a abordagem da pobreza associada aos processos educacionais ficará evidenciada tanto mais a escola pública se torne um local para o qual os mais fragilizados econômica e socialmente acorrem. Em outras palavras, quanto mais necessidade de conformar a força de trabalho para a lógica produtiva vigente, maior destaque receberá a educação. A escola, portanto, como uma instituição classista, de grande visibilidade social, palco dos conflitos de classe e espaço em que a chamada questão social, em suas múltiplas faces, se manifesta, não atuará no combate à desigualdade, mas sim na atenção à pobreza e conformação dos pobres.

A abordagem da pobreza e de outras expressões da questão social pela via da escola ganhará maior ênfase após a década de $1990,{ }^{23}$ com as políticas de ampliação quantitativa dos anos de escolarização e de estímulo à permanência no espaço escolar sugeridas por organismos internacionais e assumidas por governos (Torres, 2001) - como o então nascente Bolsa Escola. A assistencialização (Mota, 2008) da política educacional e dos espaços escolares vai, então, se tornando evidente. Uma das expressões atuais deste quadro - talvez, a mais importante por sua extensão e visibilidade — é o Programa Bolsa Família (PBF) que tem como condi-

23. Em 1990, em Jontiem, na Tailândia, organismos internacionais e governos estiveram reunidos para estabelecer metas educacionais para o século XXI. A ampliação dos níveis de escolaridade, a priorização de populações analfabetas e mulheres nas ações de escolarização foram algumas destas metas (Shiroma et al., 2000). Na sequência, os Congressos da Salamanca e a Conferência de Nova Délhi determinam padrões de ação no campo educacional, especialmente no que se refere à atenção aos pobres. 
cionalidades a matrícula e a frequência escolar. Melhor explicitando, a família usuária deve garantir a matrícula e a presença escolar mínima - em 85\% — para filhos entre 6 e 15 anos e de $75 \%$ para dependentes entre 16 e 17 anos, a fim de efetivar permanência no programa e acesso à transferência de renda.

A frequência escolar é compreendida no PBF (e em programas complementares) ${ }^{24}$ como instrumento de enfrentamento da pobreza, pelas melhores condições de acompanhamento e controle das famílias que esta prática, supostamente, proporciona; daí sua valorização. No entanto, assim como no passado, as condições operacionais e de infraestrutura em que a escola está inserida permanecem precárias e, mais do que isso, o contexto social e econômico em que a formação deste usuário acontece - visto que esta não se restringe ao espaço escolar — não é problematizada ou analisada pelo Programa.

Assim, a qualidade da educação e a infraestrutura de base para o aprendizado naquele ambiente - condições físicas do equipamento, tempo dedicado à formação, apoios disponíveis ao processo cognitivo dos educandos, remuneração dos professores, suas possibilidades de qualificação e condições de trabalho - , bem como as condições de sobrevivência do grupo familiar destas crianças e adolescentes, como partes essenciais do processo de ensino-aprendizagem, não são consideradas. Em outras palavras, as condições de vida - habitacionais, alimentares, de acesso aos demais serviços públicos, de lazer, de saúde, comunitárias, entre outras — do estudante e de sua família - seu acesso ao conhecimento, tempo dedicado à formação, acessibilidade à infraestrutura de apoio ao aprendizado ${ }^{25}$ e como este conjunto influencia suas possibilidades de desenvolvimento - não são objeto de acompanhamento (ou mesmo de análise) pelo Programa. Assim, o que está em foco no PBF são as famílias e seus indivíduos, como elementos isolados e sob avaliação, e não as condições sociais em que estes sobrevivem. Desta forma, as dificuldades frente às regras e à aprendizagem na escola são vistas como um problema a ser trabalhado (e sob a responsabilidade) da família e, poucas vezes, a instituição escolar e as condições de sobrevivência deste grupo familiar são questionadas. Este quadro nos faz pensar na condução frágil, individualizante e focalista deste progra-

24. Complementarmente ao PBF, a prefeitura do Rio de Janeiro desenvolve o Programa Família Carioca, que também transfere renda e tem como condicionalidade, além da frequência escolar, a participação dos pais e responsáveis em reuniões na escola. Em termos estaduais, temos no Rio de Janeiro o Programa renda Melhor.

25. Falamos de bibliotecas, cinemas, museus, por exemplo. 
ma e, contraditoriamente, na subutilização e desqualificação das possibilidades educacionais, de articulação e melhoria de políticas públicas contidas nele.

Esta população hoje ingressa e permanece na escola, instituição pública dotada de grande visibilidade e relevância social, especialmente se considerarmos a realidade de um país com imensa concentração de renda, poder e informação, dotado de altos níveis de analfabetismo - segundo do Censo de 2011 são 13,9 milhões de analfabetos com quinze anos ou mais, ou seja, quase $10 \%$ da população agora possuidor de melhores níveis de acesso e permanência na escola. ${ }^{26}$ Este é um grande desafio para as políticas sociais.

Entendemos que programas como o PBF revelam os contornos limitados da abordagem da questão social e das expressões do pauperismo no ambiente escolar, mas este tipo de ação não é dispensável. ${ }^{27}$ Muito ao contrário disso, precisa ser aperfeiçoado. Este programa permite, de fato, que crianças e adolescentes de famílias empobrecidas melhorem suas condições de permanência na escola e suas possibilidades de acesso a bens fundamentais. No entanto, isso não é suficiente e os profissionais de Serviço Social precisam destacar em suas ações que, somente a permanência (da qual não devemos, jamais, abrir mão) não garante o desenvolvimento das potencialidades dos estudantes e a melhoria da escola. É preciso ir além, mas sempre a partir da articulação com outras políticas sociais.

\subsection{A escola assoberbada de tarefas}

Diante da precariedade de outras políticas (e não há como negar que, em muitas localidades, somente a escola é a manifestação concreta do poder público), a instituição escolar tem assumido o papel, quase messiânico, de trazer soluções para necessidades diversas, deixando em lugar secundário sua função de prover conhecimentos científicos, históricos, da linguagem, matemáticos, do campo cultural etc. Ainda nos anos de 1980, autores como Buffa, Arroyo e Nosella (1987)

26. Ainda que os níveis de acesso à educação infantil permaneçam frágeis, segundo reconhece o próprio MEC. Sobre o tema, ver: <http://portal.mec.gov.br/seb/arquivos/pdf/Pradime/cader_tex_1.pdf >.

27. Entendemos que um projeto de desenvolvimento nacional, em um país dotado de tão significativas desigualdades, deverá contemplar ações no campo da transferência de renda. Portanto, políticas como o PBF não devem ser, segundo nossa compreensão, dispensadas, mas aperfeiçoadas no sentido de sua universalização, melhoria dos recursos transferidos, da aproximação com os usuários e do controle social. 
fizeram análise crítica a este respeito. Em reflexão atualizada, datada de 2001, Arroyo recoloca este mesmo debate, revelando sua importância ao afirmar que a escola tem se tornado um lugar de improvisação e emergencialismos, onde as possibilidades de aprendizagem efetiva estão fragilizadas.

Segundo estes autores, ao dar respostas a inúmeras demandas (e acrescentamos, sem que esta instituição receba suporte para tanto), a escola acaba convertida em um modelo precário de ensino, produzindo "quase alfabetizados" $28 \mathrm{e}$ improvisando respostas para as diversas expressões da questão social. Seu papel reflexivo e socializador do conhecimento produzido, assim como seu suporte para leitura de realidade, ficam secundarizados e esmaecidos, frente à necessidade de receber crianças e adolescentes e de prepará-los para a sociabilidade atual. Mais do que formar, a escola passa a informar valores e atitudes para esta nova ordem. Neste sentido, lembramos a criação de uma nova semântica em torno da formação, conforme reflexão de Frigotto (2001). Segundo esta, novos conceitos afinados à ordem atual são pensados: o estudante passa a perseguir competências específicas, muitas vezes limitadas a aspectos atitudinais, em detrimento do acesso ao conhecimento amplo, capaz de localizá-lo como sujeito frente ao mundo. A educação como relação social fica limitada a formar favoravelmente (e precariamente) para a ordem social vigente e a escola, como instituição, experimenta um acúmulo de tarefas.

Este chamamento à escola "que soluciona todos os problemas", não por acaso, coincide com o aprofundamento das políticas neoliberais na década de 1990, na ascensão e na materialização deste tipo de pensamento, quando ocorre o aprofundamento da funcionalidade da educação ao mercado e a intensificação da abordagem moralizante do fenômeno pobreza (Yazbek, 1993). A política educacional terá representada, em seu interior, a necessidade de formar para a reestruturação produtiva, para o trabalho flexível e precário, para a lógica produtivista e individualista e para o alívio das tensões de classe (Gentili, 1996), ainda que diante da resistência dos trabalhadores da educação e de setores da sociedade a este processo. ${ }^{29}$

28. O número de analfabetos funcionais no Brasil é alarmante. Segundo a PNAD (2009), 25\% da população com mais de 15 anos experimenta esta condição.

29. Neste campo, queremos lembrar a ação do Sepe/RJ (Sindicato Estadual dos Profissionais da Educação) e da Apeoesp/SP (Sindicato dos Professores do Ensino Oficial do Estado de São Paulo), em especial na década de 1990 . 
Neste mesmo contexto é importante lembrar as recomendações do Banco Mundial ${ }^{30}$ quanto à pobreza nas chamadas economias periféricas (Banco Mundial, 2001). Elas falam do acesso dos países periféricos a uma educação rápida, profissionalizante, voltada para o mercado e para os vínculos informais. Não podemos, porém, conferir a estes organismos internacionais um papel maniqueísta — de algoz solitário dos países periféricos - uma vez, que de fato, suas recomendações sociais e econômicas somente se efetivam com o suporte da burguesia nacional e de sua representatividade nos governos.

Estes organismos estimulam, ainda, a abordagem da pobreza, a partir da melhoria dos índices educacionais. Neste sentido, compreende-se que a educação é um instrumento de ação importante no chamado "alívio da pobreza". Este tipo de ação está embasado na percepção de que o pobre é alguém privado de capacidades materiais e intelectuais para gerir adequadamente sua vida. Sob esta lógica os fundamentos da desigualdade não são questionados, visto que o foco fica no "alívio da pobreza", no combate a sua expressão absoluta e na criação de estratégias para torná-la menos agressiva e visível. Neste sentido, através da educação formal e informal, os pobres devem ser orientados a uma conduta mais proativa, adequada e empreendedora diante da vida. ${ }^{31}$

Nesta mesma linha de compreensão, os pobres passam a ser vistos como recurso potencial e abundante (Altmann, 2002) — no sentido produtivista do termo. Em outras palavras, os pobres passam a ser entendidos como um recurso de grande potencial econômico a ser explorado, o que implicará uma abordagem diferenciada deles. Mais do que um problema evidente e temível, mais do que um risco à "esquerdização" das relações sociais (Ammann, 1987), os pobres são redescobertos como recursos humanos e possibilidades produtivas. Suas capacidades para o empreendedorismo, geração de renda e para o colaboracionismo acrítico do mundo do trabalho serão valorizadas. Haverá, portanto, uma fetichização do fenômeno da pobreza.

Para que este quadro de cooptação das subjetividades dos pobres seja materializado, o acesso ao trabalho, ainda que precário e desprotegido, torna-se uma recomendação essencial, assim como a melhoria dos níveis educacionais e sua

30. O Banco Mundial conta hoje com mais de 160 países-membros, entre eles o Brasil. Sua estrutura decisória está baseada nos recursos financeiros disponibilizados ao órgão, o que define que cerca de $50 \%$ dos votos estejam nas mãos de $5 \%$ dos países. A estrutura do Banco Mundial reproduz, portanto, as relações econômicas e de poder existentes entre países centrais e periféricos.

31. Em pesquisa realizada junto à experiência da inserção produtiva dos Cras (Centro de Referência de Assistência Social), observamos a presença deste tipo de discurso (Lessa, 2011). 
profissionalização. Haverá, assim, como já discutido aqui, uma revalorização da formação, especialmente aquela que se volta para os trabalhadores dos níveis mais elementares da produção, estimulando-os a uma requalificação permanente (Lessa, 2011). Neste sentido, o acesso ao trabalho e à escolarização - qualquer trabalho e qualquer escola - como forma de combate à pobreza recebe destaque.

As políticas educacionais, neste contexto, serão aliadas fundamentais no projeto de tornar os pobres mais produtivos e integráveis à lógica do capital. Tais ações terão forte conteúdo moral, sendo reveladoras de uma nova pedagogia instaurada para a manutenção da ordem hegemônica do capital (Neves, 2005), formada por uma ética baseada no mercado, no consumo, na competitividade, na individualidade e na produtividade.

A escola pública terá importante destaque neste processo, despontando como locus importante de abordagem dos pobres - prática bastante comum nos países centrais desde a década de 1960 (Connel, 1995) - , constituindo-se em uma das instituições principais no trato da questão. Para os mais pobres, as políticas educacionais serão organizadas de modo a tornar o aprendizado mais acessível, sem grandes exigências, palatável, produtivista, independentemente da qualidade e do aligeiramento da formação.

Para tanto, o acesso e a permanência neste ambiente serão facilitados através de transferência de renda e de programas no contraturno, mas as escolas permanecerão sucateadas, desqualificadas e esvaziadas na função pública de educar. Como afirma Frigotto (1993), um modelo de escola pouco atraente e de má qualidade está em consonância com a divisão internacional do trabalho na qual o Brasil se insere como um país periférico, que não produz ciência e tecnologia em larga escala. Educamos para o emprego simples e precário, para a vida alienada e conformada. Desta forma, este modelo de educação simplificadora, aligeirada e precarizada está em consonância com o quadro traçado.

Neste contexto de maximização do papel da escola e da educação, mas não de sua qualidade, as instituições escolares são transformadas em espaços em que cabem quase todas as aprendizagens e onde o ato de educar pode ser realizado por todos. Neste sentido, voluntários podem oferecer aprendizagens esportivas, culturais, artísticas, ${ }^{32}$ religiosas e até de suporte às disciplinas, numa clara alusão ao fato de que

32. Outro exemplo notório deste processo é o Projeto Amigos da Escola da Fundação Roberto Marinho. Esta é uma iniciativa através da qual voluntários adentram o ambiente escolar oferecendo experiências diversas a serem incorporadas à dinâmica daquele espaço. 
educar é uma tarefa simples, não especializada, que pode ser realizada por qualquer um, em claro processo de "desprofissionalização" e desqualificação desta atividade.

Nestas mesmas escolas, Organizações não Governamentais oferecem atividades no contraturno - como o Projeto Acelera Brasil da Fundação Ayrton Senna, executado em diversos municípios brasileiros, inclusive o Rio de Janeiro. O citado projeto tem como proposta adequar a relação idade-série nos anos iniciais, a partir de apostilas pré-formuladas. Em outras palavras, como o próprio nome revela, o projeto se propõe a acelerar a aprendizagem de estudantes com histórico de "dificuldades" neste campo —dificuldades essas que devem ser compreendidas de forma ampla, podendo estar relacionadas às condições de vida, além de aspectos cognitivos e de saúde - , o que não nos parece estar ocorrendo. Entendemos tratar-se de uma proposta de formação verticalizada pela $\mathrm{ONG}$, focalizada no educando, a partir de um modelo único, que não percebe particularidades dos estudantes, viabilizada através da transferência de recursos públicos para o setor privado, o que nos inspira, no mínimo, preocupação. Este quadro torna ainda mais complexo o acesso da classe trabalhadora e, em seu interior, dos mais fragilizados economicamente, que já experimentam condições de sobrevivência tão complexas e adversas à formação propedêutica, a despeito da ampliação de seu acesso à escola.

Inúmeros, portanto, são os desafios para os profissionais da educação, dentre eles, os assistentes sociais. Neste sentido, é fundamental que possamos refletir sobre nosso trabalho, nesta política, sua inserção na sociedade contemporânea, e sobre a população usuária, suas condições de vida e participação política, reconhecendo possibilidades de resistência a este processo de fragilização da educação. Devemos reconhecer, assim, contraditoriamente, que educação é tensão e contradição, reposição da ordem e possibilidade de enfrentá-la. Sua materialização está em permanente disputa na sociedade.

\section{Consideraç̧ões finais}

A relação entre o Serviço Social, a política educacional e a escola pública precisa ser compreendida em suas determinações de ordem econômica, social e política, considerando suas potencialidades e limitações no contexto do capitalismo neste novo milênio, que a despeito de seus avanços tecnológicos e de substituição do trabalho vivo pelo trabalho morto, para otimização dos processos de acumulação 
de capital, ainda precisa de uma educação que prepare homens e mulheres para seus processos de produção e reprodução social. Na realidade contemporânea, portanto, educar é uma tarefa central para o capitalismo, visto que este solicita uma formação propedêutica para uma minoria e um aprendizado simplificado e voltado para o mercado para as grandes massas populacionais (Kuenzer, 2002).

Como resistência a este processo, é importante reforçar o quão essencial é a instituição escolar e o quão vital esta pode ser na construção de um projeto de uma nação soberana, democrática, que organiza seus pilares econômicos na valorização do conhecimento, da ciência e na busca do combate à desigualdade. No entanto, educar é um processo amplo e complexo, que extrapola os muros escolares; por isso a importância da criação de retaguardas e de outras políticas sociais e serviços no entorno da política educacional.

Entendemos, portanto, que a estruturação de retaguardas institucionais e de redes de serviços públicos de qualidade para a abordagem dos problemas que se manifestam na educação e na escola é urgente. Responsabilizar e denunciar governos por sua inadequada gestão, valorizar a luta dos seus trabalhadores e a participação das famílias e da sociedade no interior dos espaços educacionais e nos Conselhos de Direitos são caminhos neste sentido. Estamos falando, portanto, em sentido amplo, das lutas por seu adequado financiamento e controle social e da articulação com outras políticas públicas. Neste mesmo sentido, no cotidiano de nossa prática, falamos da importância de sermos profissionais de conduta democrática e olhar indagador/pesquisador, que fugimos do senso comum que naturaliza a desinformação do usuário e a frágil qualidade da escola pública, capazes de dialogar com a população que atendemos, entendendo-a como resultado de um processo longo de destituição, que apesar de tudo sobrevive, resiste e luta por dias melhores.

As dificuldades no sentido da organização de uma política educacional e de uma escola de qualidade e comprometida com uma educação emancipadora são muitas, mas isso não quer dizer que não possamos pensar a educação segundo os fundamentos do projeto ético-político que orienta nossa profissão: a justiça, o direito, a igualdade, a não discriminação, o respeito à pluralidade, o diálogo intelectual com outras categorias. Pelo contrário. É sobre este quadro contraditório, conflituoso, é sobre este fio da navalha que construímos nossa ação profissional, sendo também este o espaço em que a educação se constrói. Como afirma Saviani (1995, p. 87), a desigualdade pode ser convertida em igualdade através da educação, mas 
não "em termos isolados, mas articulada com as demais modalidades que configuram a prática social global".

\section{Recebido em 20/7/2012 - Aprovado em 10/12/2012}

\section{Referências bibliográficas}

ALMEIDA, Ney Luiz Teixeira de. Serviço Social e política educacional: um breve balanço dos avanços e desafios desta relação, 2003. Disponível em: <www.cress-mg.org.br/textos/> . Acesso em: $1^{\circ}$ nov. 2004.

ALTMANN, Helena. Influências do Banco Mundial no projeto educacional brasileiro. Educação e Pesquisa. São Paulo, v. 28, n. 1, jan./jun. 2002.

AMMANN, Safira Bezerra. Ideologia do desenvolvimento de comunidade. 6. ed. São Paulo: Cortez, 1987.

ANTUNES, Ricardo. Os sentidos do trabalho: ensaio sobre a afirmação e negação do trabalho. São Paulo: Boitempo, 1999.

ARANTES, Ester Maria de Magalhães; FALEIROS, Eva Terezinha. Subsídios para uma história da assistência privada dirigida à infância no Brasil. In: PILOTTI, Francisco; RIZZINI, Irene. A arte de governar crianças no Brasil. Rio de Janeiro: Amais, 1995.

ARROYO. Miguel G. Trabalho. Educação e teoria pedagógica. In: FRIGOTTO, Gaudêncio (Org.). Educação e crise do trabalho: perspectivas de final de século. Petrópolis: Vozes, 1998.

. Educação em tempos de exclusão. In: GENTILI, Pablo; FRIGOTTO, Gaudêncio (Org.). A cidadania negada: políticas de exclusão na educação e no trabalho. São Paulo: Cortez, 2001.

BANCO MUNDIAL. Relatório sobre o desenvolvimento mundial. Luta contra a pobreza 2000/2001. Panorama geral. Washington, DC, 2001. Disponível em: $<$ http://siteresources. worldbank.org/INTPOVERTY/Resources/WDR/Poroverv.pdf >. Acesso em: 22 nov. 2008. BIANCHETTI, Lucídio. Da chave de fenda ao laptop. Tecnologia digital e novas qualificações: desafios à educação. Petrópolis: Vozes/UniTrabalho/Editora da UFSC, 2001.

BOURDIEU, Pierre. Contrafogos: táticas para enfrentar a invasão neoliberal. Rio de Janeiro: Jorge Zahar Editores, 1998. 
BRASIL. Lei de Diretrizes e Bases da Educação (LDB). Lei n. 9.394, de 20 de dezembro de 1996. Estabelece as Diretrizes e Bases da Educação Nacional. DOU, 23 dez. 1996. Disponível em: <http://www.planalto.gov.br/ccivil_03/Leis/L9394.htm>. Acesso em: 10 fev. 2011.

. IBGE. Pesquisa nacional por amostra de domicílios. Sintese de Indicadores, 2009. Disponível em: <http://www.ibge.gov.br/home/estatistica/populacao/trabalhoerendimento/ pnad2009/pnad_sintese_2009.pdf $>$. Acesso em: 8 jan. 2013.

. Lei n. 12.101, de 27 de novembro de 2009. Dispõe sobre a certificação de entidades beneficentes de assistência social. Disponível em: $<$ http://www.planalto.gov.br/ccivil_03/_ ato2007-2010/2009/lei/112101.htm>. Acesso em: 27 jun. 2012.

Brasil, MEC. Censo registra 51,5 milhões de matriculados em 2010. Disponível em: $<$ http:// portal.mec.gov.br/index.php?option=com_content\&view=article\&id=16179>. Acesso em: 20 jun. 2012.

. Ministério do Desenvolvimento Social e Combate à Fome. Secretaria Nacional de renda e Cidadania. Departamento de Operação. Coordenação Geral de Apoio à Gestão Descentralizada. Caderno do IGD-M. Brasília, abr. 2012. Disponível em: <www.mds.gov. br/bolsafamilia/.../Caderno\%20do\%20IGDM\%202012...>. Acesso em: 8 jan. 2013.

. Lei n. 12.677/2012. Dispõe sobre a criação de cargos junto ao MEC. Disponível em: <http://www.lexml.gov.br/urn/urn:lex:br:federal:lei:2012-06-25;12677>. Acesso em: 3 jul. 2012.

BUFFA, Ester; ARROYO, Miguel; NOSELLA, Paolo. Educação e cidadania: quem educa o cidadão? São Paulo: Cortez, 1987.

CAMPOS, Maria Malta. Educação e políticas de combate à pobreza. Revista Brasileira de Educação, n. 24, 2003.

CHESNAIS, François. A mundialização do capital. São Paulo: Xamã, 1996.

CHOSSUDOVSKY, Michel. A globalização da pobreza: impactos das reformas do FMI e do Banco Mundial. São Paulo: Moderna, 1999.

CONNEL, R. W. Pobreza e Educação. In: GENTILI, Pablo. Pedagogia da exclusão: crítica ao neoliberalismo em educação. 8. ed. Petrópolis: Vozes, 1995. p.11-42.

CUNHA, Luis Antonio. Educação, estado e democracia no Brasil. 2. ed. São Paulo: Cortez, 1995.

DAVIES, Nicholas. Verbas da educação: o legal × o real. Niterói: Ed. Eduff, 2000.

D’ELBOUX, Yannik. A fila também anda nas escolas particulares. Revista Gestão Educacional. Disponível em: $<\mathrm{http}$ ://www.gestaoeducacional.com.br/view/action/mostrarMateria. php?cod=1830>. Acesso em: 10 jul. 2012. 
FRIGOTTO, Gaudêncio. A produtividade da escola improdutiva. São Paulo: Cortez, 1993. . Educação e crise do capitalismo real. São Paulo: Cortez, 1995.

. Educação e formação humana. Ajuste neoconservador e alternativa democrática. 4. ed. In: GENTILI, Pablo; SILVA, Tomaz Tadeu da (Org.). Neoliberalismo, qualidade total e educação: visões críticas. 4. ed. Petrópolis: Vozes, 1996.

. Os delírios da razão. Crise do capital e metamorfose conceitual no campo educacional. In: GENTILI, Pablo. Pedagogia da exclusão: crítica ao neoliberalismo em educação. 8. ed. Petrópolis: Vozes, 2001.

. A dupla face do trabalho: criação e destruição da vida. In: FRIGOTTO, Gaudêncio; CIAVATTA, Maria (Org.). A experiência do trabalho e a educação básica. Rio de Janeiro: DP\&A, 2002.

FUNDAÇÃO GETÚlIO VARGAS. Centro de Políticas Sociais. Mapa da Fome. Disponível em: <www.rebidia.org.br/novid/FGV_MFOME.htm>. Acesso em: 11 nov. 2004.

GENTILI, Pablo. O discurso da qualidade como nova retórica conservadora no campo educacional. In: GENTILI, Pablo; SILVA, Tomaz Tadeu da (Org.). Neoliberalismo, qualidade total e educação: Visões críticas. 4. ed. Petrópolis: Vozes, 1996.

. Adeus à escola pública. A desordem neoliberal, a violência do mercado e o destino da educação das maiorias. (Org.). Pedagogia da exclusão: crítica ao neoliberalismo em educação. 8. ed. Petrópolis: Vozes, 2001.

GONÇALVES, Reinaldo. Crise econômica: radiografia e soluções para o Brasil. Rio de Janeiro: Fundação Lauro Campos, 2008. Disponível em: <http:/www.socialismo.org.br/ portal/economia-e-infra-estrutura/101-artigo/604-crise-economica-radiografia-e-solucoes-para-o-brasil>. Acesso em: 11 dez. 2009.

GUERRA, Yolanda. A formação profissional frente aos desafios da intervenção e das atuais configurações do ensino público, privado e a distância. Serviço Social \& Sociedade, São Paulo, n. 104, p. 715-736, 2010.

HARVEY, David. A condição pós-moderna. São Paulo: Loyola, 2003.

HOBSBAWM, Erick. A era dos extremos: o breve século XX. São Paulo: Companhia das Letras, 1995.

IAMAMOTO, Marilda V. O Serviço Social na contemporaneidade: trabalho e formação profissional. 7. ed. São Paulo: Cortez, 2004.

INEP (Instituto Nacional de Estudos e Pesquisas Educacionais). Diagnóstico da situação educacional de jovens e adultos. Brasília: Inep, 2000. 
INEP. Censo 2000. O Globo, 17 dez. 2003.

KOSIK, Karel. Dialética do concreto. São Paulo: Paz e Terra, 1995.

KUENZER, Acacia. Ensino de segundo grau. O trabalho como princípio educativo. São Paulo: Cortez, 2001.

. Pedagogia da fábrica: as relações de produção e a educação do trabalhador. São Paulo: Cortez, 2002.

LESSA, Simone Eliza do Carmo Lessa. A formação via PNQ e inserção produtiva dos Cras: a reposição empobrecida e emergencial da qualificação de trabalhadores. Serviço Social \& Sociedade. São Paulo, n. 106, abr./jun. 2011.

MACEDO, Myrtes de Aguiar; BRITO, Sebastiana Rodrigues de. Transferência de renda: nova face da proteção social? Rio de Janeiro: Editora PUC-Rio; São Paulo: Loyola, 2004.

MANACORDA, Mario Alighiero. História da educação. 8. ed. São Paulo: Cortez, 2000.

MANFREDI, Silvia Maria. Educação profissional no Brasil. São Paulo: Cortez, 2003.

MARX, Karl. O capital. São Paulo: Nova Cultural, 1987. v. I e III. (Col. Os Economistas.)

MÉSZÁROS, István. Para além do capital. Trad. de Paulo Cezar Castanheira e Sérgio Lessa. Prefácio Ricardo Antunes. São Paulo: Boitempo; Campinas: Ed. Unicamp, 2002. 1.104 p. (Col. Mundo do Trabalho.)

METADE DOS ESTUDANTES TERMINA O ENSINO MÉDIO NA IDADE ERRADA. Disponível em: $<$ http://noticias.r7.com/vestibular-e-concursos/noticias/metade-dos-estudantes-termina-o-ensino-medio-na-idade-errada-20111130.html>. Acesso em: 14 jan. 2011.

MONTAÑO, Carlos. Terceiro Setor e a questão social: crítica ao padrão emergente de intervenção social. 2. ed. São Paulo: Cortez, 2003.

MORAES, Carmen Silva Vidigal. Instrução popular e ensino profissional: uma perspectiva histórica. In: VIDAL, Diana Gonçalves; HILSDORF, Maria Lucia Spedo (Org.). Brasil 500 anos. Tópicos em história da Educação. São Paulo: Edusp, 2001.

MOTA, Ana Elisabete (Org.). O mito da assistência social: ensaio sobre Estado, política e sociedade. São Paulo: Cortez, 2008.

NASCIMENTO, Arlindo Melo do. População e família brasileira: ontem e hoje. In: ENCONTRO NACIONAL DE ESTUDOS POPULACIONAIS (ABEP), 15., 2006. Disponível em: $<$ http://143.107.236.240/disciplinas/SAP5846/populacao_familia_nascimento_abep06. pdf $>$. Acesso em: 3 jun. 2012.

NETTO, Jose Paulo. Ditadura e Serviço Social: uma análise do Serviço Social no Brasil, pós-64. São Paulo: Cortez, 1991. 
NETTO, José Paulo. Capitalismo monopolista e Serviço Social. São Paulo: Cortez, 2001.

NEVES, Lucia Maria Wanderley. Brasil 2000. Nova divisão de trabalho na educação. São Paulo: Xamã, 2000.

(Org.). A nova pedagogia da hegemonia: estratégias do capital para educar o consenso. São Paulo: Xamã, 2005.

NOSELLA, Paolo. A escola de Gramsci. Porto Alegre: Artes Médicas, 1992.

. A escola brasileira no final do século: Um balanço. In: FRIGOTTO, Gaudêncio. Educação e crise do trabalho: perspectivas de final de século. Petrópolis: Vozes, 1998.

O GLOBO, 7 dez. 2010. Brasil fica em 53 lugar em avaliação internacional de alunos. Disponível em: <http://g1.globo.com/jornal-nacional/noticia/2010/12/brasil-fica-em-53-lugar-em-avaliacao-internacional-de-alunos-de-65-paises.html>. Acesso em: 10 dez. 2010. OLIVEIRA, Ramon. Agências multilaterais e a educação profissional brasileira. Campinas: Alínea, 2006.

ORGANIZAÇÃO DAS NAÇÕES UNIDAS NO BRASIL, PNUD. Abet, 1998. Disponível em: <www.pnud.org.br/idh/>.

RAMOS, Marise Nogueira. Pedagogia das competências: autonomia ou adaptação? São Paulo: Cortez, 2001.

RODRIGUES, José. O moderno príncipe industrial: o pensamento pedagógico da Confederação Nacional da Indústria. Campinas: Autores Associados, 1998.

SAVIANI, Demerval. Escola e democracia. 29. ed. Campinas: Autores Associados, 1995. . A Nova Lei da Educação (LDB). Trajetória, limites e perspectivas. Campinas: Autores Associados, 2000.

SHIROMA, Eneida Oto; MORAES, Maria Célia de; EVANGELISTA, Olinda (Org.). Política educacional. Rio de Janeiro: DP\&A, 2000.

SILVA, Maria Ozanira Silva e. Pobreza, desigualdade e política pública: caracterizando e problematizando a realidade brasileira. Katálysis, Florianópolis, v. 13, n. 2, jul./dez. 2010.

TORRES, Rosa Maria. Educação para todos: a tarefa por fazer. Porto Alegre: Artes Médicas, 2001.

WACQUANT, Löic. Prisões da miséria. Rio de Janeiro: Zahar, 2001.

YAZBEK, Maria Carmelita. Classes subalternas e assistência social. São Paulo: Cortez, 1993. . Fundamentos históricos e teórico-metodológicos do Serviço Social. Serviço Social: direitos e competências profissionais. Brasília, CFESS/ABEPSS, 2009. 